\title{
Pregnancy Status at Time of Illness or Condition
}

National Cancer Institute

\section{Source}

National Cancer Institute. Pregnancy Status at Time of Illness or Condition. NCI

Thesaurus. Code C138960.

The pregnancy status of an individual at the time of an illness or condition. 